\title{
Who Owns the Content and Who Runs the Risk? Dynamics of Teacher Change in Teacher-Researcher Collaboration
}

\author{
Karim Hamza $^{1}$ - Jesús Piqueras ${ }^{1}$ - Per-Olof Wickman ${ }^{1}$ • \\ Marcus Angelin ${ }^{2}$
}

Published online: 14 June 2017

(C) The Author(s) 2017. This article is an open access publication

\begin{abstract}
We present analyses of teacher professional growth during collaboration between science teachers and science education researchers, with special focus on how the differential assumption of responsibility between teachers and researchers affected the growth processes. The collaboration centered on a new conceptual framework introduced by the researchers, which aimed at empowering teachers to plan teaching in accordance with perceived purposes. Seven joint planning meetings between teachers and researchers were analyzed, both quantitatively concerning the extent to which the introduced framework became part of the discussions and qualitatively through the interconnected model of teacher professional growth. The collaboration went through three distinct phases characterized by how and the extent to which the teachers made use of the new framework. The change sequences identified in relation to each phase show that teacher recognition of salient outcomes from the framework was important for professional growth to occur. Moreover, our data suggest that this recognition may have been facilitated because the researchers, in initial phases of the collaboration, took increased responsibility for the implementation of the new framework. We conclude that
\end{abstract}

Karim Hamza

karim.hamza@mnd.su.se

Jesús Piqueras

jesus.piqueras@mnd.su.se

Per-Olof Wickman

per-olof.wickman@mnd.su.se

Marcus Angelin

angelin@kth.se

1 Department of Mathematics and Science Education, Stockholm University, 10691 Stockholm, Sweden

2 House of Science (Vetenskapens Hus), AlbaNova University Center/KTH, 10691 Stockholm, Sweden 
although this differential assumption of responsibility may result in unequal distribution of power between teachers and researchers, it may at the same time mean more equal distribution of concrete work required as well as the inevitable risks associated with pedagogical innovation and introduction of research-based knowledge into science teachers' practice.

Keywords Teacher professional growth $\cdot$ Science teaching $\cdot$ Collaboration $\cdot$ Risk $\cdot$ Agendasetting dilemma

\section{Introduction}

This article tells a story of teacher professional growth during a teacher professional development (TPD) project consisting of collaboration between grade 7-9 science teachers and science education researchers. Through detailed analyses of the change dynamics (Clarke and Hollingsworth 2002) of the collaboration, potentially important messages emerge concerning how to balance the distribution of power, the responsibilities of implementation of research-based knowledge, and the risks connected to pedagogical innovation between the participants in teacher-researcher collaborations.

School-university collaborations have taken on a variety of shapes during the past 30 years, ranging from state and nation-wide efforts to local initiatives in which small groups of teachers and researchers collaborate around a common area of interest (Callahan and Martin 2007). Such collaborations and partnerships bring common and well-known challenges with them, ranging from concrete issues such as timeallocation and funding to issues more to do with various dynamics of the collaboration and dilemmas concerning relations, roles, and responsibilities in the group (Erickson et al. 2005). In particular, differences in culture and forms of knowledge valued seem to work against the development of shared professional communities between educators from universities and schools (Cuban 1992; Szteinberg et al. 2014). The differences are commonly cast in terms of differential power relations and gains, with teachers usually coming out worst, facing the risk of being disempowered and denied access to knowledge relevant to their perceived problems (Butler et al. 2004; Clark et al. 1996; Hardy and Melville 2013). In science education in particular, a near universal consensus is emerging that successful TPD should be peer-led, teacherdriven, inquiry-based, and grounded in local school culture (Mansour et al. 2014; van Driel et al. 2012; Tytler 2006). As a result, several successful initiatives for collaborative TPD aiming at building on science teachers' expertise and authority, focusing on co-construction of knowledge and on carefully negotiating the roles of teachers and researchers, have been carried out (DiGisi et al. 1999; McNicholl 2013; Richmond and Manokore 2011; Stolk et al. 2011).

Yet, despite successful efforts, striking the right balance between participants concerning power and responsibilities remains a key challenge of teacher-researcher collaborations (Erickson et al. 2005). Working with language teachers, Virginia Richardson touched on this issue as she elaborated the so called agenda-setting dilemma of TPD involving collaboration between outside experts and teachers (Richardson 1992). The agenda-setting dilemma arises in collaborations when the researchers pursue two aims which, at the same time, complement and compete with each other. On the one hand, the researchers bring something which they think will empower teachers in their day-to-day work. On the other hand, as we have seen, a central 
part of such empowerment is precisely that teachers are actually able to influence the content, purposes, and forms of the collaboration. Thus, Richardson (1992) asks:

Who, then, owns the content? Who is (are) the expert(s)? The second goal [i.e. that the participants own the content and process] suggests that power must be shared equally by the participants, and that each participant contributes expertise. However, with a preconceived and negotiated formal content that is seen to reside in the staff developers, the goal of shared power may be difficult to reach. (p. 288)

In the present study, aspects resembling Richardson's dilemma became evident in the course of a teacher-researcher collaboration which set off with the explicit purpose of being grounded in the participating teachers' expertise and needs. In order to accommodate what the teachers wanted to accomplish through the collaboration, namely to improve their students' learning in science, the researchers decided to provide a newly developed conceptual framework for taking students' learning progression into account in planning a science unit. The framework, called "organizing purposes" (Johansson and Wickman 2011; Wickman and Ligozat 2010), was developed specifically to support teachers in choosing content that leads, bit by bit, towards the overarching goal of a science unit. Hence, presenting this framework to the teachers was seen by the researchers as a means to increase the teachers' authority over their practice on the matters that they had requested. However, to begin with, this conceptual framework was not considered useful by the teachers. Thus, the researchers were faced with a dilemma: on the one hand, to introduce a framework which the teachers did not initially appreciate but that was aimed at helping the teachers accomplish precisely that which they wanted to achieve for their students while, on the other hand, to honor teachers' shared ownership over the content of the collaboration. It is the dynamics between changes in the teachers' practice and changes in the distribution of power and assumption of responsibility during the collaboration that constitutes the core results of the study.

The study is thus a response to an acknowledged need to learn more about the processes of science TPD, both concerning teacher learning and the complex relationships between the participants in school-university collaborations (Mansour et al. 2014; Stolk et al. 2011; van Driel et al. 2012). We address the following broad research question: What are the dynamics of science teacher change during teacher-researcher collaboration, following the introduction of a new conceptual framework?

\section{Procedure}

Data come from the 3-year project Supporting Teachers' Agency and Learning in Teaching Secondary School Science (TALES) aiming at studying science TPD in collaboration with science education researchers. A particular interest of this project is to study the dynamics of introducing educational research into experienced and successful science teachers' practice. The project consisted of two subprojects in Stockholm and Gothenburg. This article presents results from a sequence of events that became salient during the initial stages of the Stockholm part.

In Stockholm, three (initially four) science teachers and four researchers (three science education researchers and one chemistry expert) regularly met to jointly plan and evaluate three cycles of teaching in chemistry (first two cycles) and physics (last cycle) in years 7-9 in a 
public school in the suburbs of Stockholm. All teaching was conducted by the teachers. Meetings and lessons were video and audio recorded. The meetings were transcribed verbatim in their entirety, as were selected lessons. The lessons were recorded for the purpose of evaluating one cycle of teaching in order to make changes and improvements to the following cycle. The teachers, Ola, Jenny, and Andreas, taught one cycle each, and in that order. Erik went on parental leave soon before Jenny began her teaching.

The school was chosen since it had previously been involved in school development projects with our department. Thus, we knew that the teachers planned their teaching together. In particular, they had developed a series of science units characterized by Roberts's (1982) two curriculum emphases everyday coping and science, technology, and society. Examples of units are "The moisturizer," in which students learn about solubility, intermolecular forces, and properties of matter with the overarching aim of producing their own moisturizer, and "The cottage," in which students learn about construction, electricity, and mathematics as they design and construct a model of a cottage. It is significant that these teachers and their work were considered exemplary by the school district. Thus, the school received visits from other schools wanting to implement similar ideas, and one of the teachers (Ola) had just received a national award for being an exemplary teacher, issued by the Royal Swedish Academy of Sciences.

The teachers joined the project with the explicit ambition to "fine-tune" their existing (already exemplary) teaching in order to get the students to learn more from their science units. They knew from the beginning that the researchers would introduce a conceptual framework specifically designed to help teachers modify their teaching according to perceived needs. They also knew that the joint planning meetings would be recorded and that the process through which they changed their practice of planning teaching would be the focus of the analysis. In the event, the teachers chose to take the opportunity to also develop a new unit about the chemistry of food, which got the name "Why can't we survive exclusively on French fries?" This unit included learning about the different chemical constituents of food and how we are able to know what they are, their constitution, and in what proportions they occur in different food. It contained lectures, practical work with molecular models, and laboratories. This unit became the content in the first two cycles, taught by Ola and Jenny, whereas the third cycle, taught by Andreas, was about an already existing unit about electricity and construction ("The cottage"). Here we present results from the initial 6 months of the collaboration, consisting of the entire first cycle and the planning of the second one (Fig. 1).

Before the first meeting, the researchers provided the teachers with a text presenting the new framework, the so-called organizing purposes framework, for planning and evaluating teaching according to defined purposes. During the first meeting, the text was discussed and connections were made to the teachers' existing practice. Also during that meeting, efforts to outline the new teaching unit on the chemistry of food began. Planning the new unit, with the aim that Ola would teach it after the summer holiday, was also the focus in the following two meetings 2 and 3 before the summer, as well as one directly when school started again at the end of August (meeting 4). After that, Ola taught the unit and two of the researchers recorded the lessons. During that time, the researchers also transcribed and analyzed Ola's teaching, and when he had finished the unit, we were ready to evaluate the first cycle and begin planning the

\begin{tabular}{|c|c|c|c|c|c|c|c|c|c|}
\hline April & May & June & July & August & September & Octol & & & November \\
\hline M1 & M2 & M3 & & M4 & Ola's teaching & M5 & M6 & M7 & Jenny's teaching \\
\hline $4 / 14$ & $5 / 12$ & $5 / 26$ & & $8 / 17$ & $9 / 19-10 / 13$ & $10 / 1$ & $10 / 20$ & $10 / 28$ & $11 / 14-$ \\
\hline
\end{tabular}

Fig. 1 Timeline of the collaboration 
next one (which Jenny was going to teach). This evaluation and new planning was the subject of the three following meetings (5-7) in October. The data for the present study end with meeting 7, just before Jenny began teaching. Ola, as the head teacher, chaired all meetings.

\section{Organizing Purposes-the New Conceptual Framework}

The theoretical and empirical basis for the conceptual framework introduced to the teachers was developed over a period of 15 years within the Swedish pragmatist tradition of science education research, through a large number of detailed studies of the processes by which K-12 and university students learn new science content through interactions with material resources as well as with peers and teachers (Hamza and Wickman 2009; Hamza 2013; Lidar et al. 2006; Lundqvist et al. 2009; Jakobson and Wickman 2007; Lundegård and Wickman 2007; Orlander and Wickman 2011; Piqueras et al. 2011; Wickman 2004, 2006; Wickman and Östman 2002). A central outcome from this research is the requirement for students to establish continuity between different parts of a learning experience in such a way that the present situation becomes connected both to what students bring to it and what they anticipate as a result of the experience. The concepts of the framework support the teacher in planning and managing lessons so that this continuity is achieved.

The framework of organizing purposes (Johansson and Wickman 2011) distinguishes between proximate and ultimate purposes. This distinction is not absolute and, thus, it is not possible to ask whether a certain purpose per se belongs to either category. Rather, the framework emphasizes the importance that the teacher, in planning lessons, considers both what students may be able to achieve on the basis of what they already know and can do and what they should know or be able to do a little later in the lesson or sequence of lessons. Thus, the idea is that the teacher plans for an initial activity of which students are already able to understand the purpose. Such a purpose is labeled proximate since it is required to be "close" to students' previous experiences. At the same time, the teacher needs to consider what new content students should learn as a result of the initial activity. This constitutes the ultimate purpose of the activity. Often, ultimate purposes need to be broken down into smaller segments called main purposes. The task for the teacher, then, is to plan and manage lessons in such a way that the proximate purpose (a) is indeed embraced by the students, which is expressed formally through it becoming an end-in view, and (b) is slowly and gradually transformed into another activity which lies closer to the main or ultimate purposes. If this transformation is achieved, the purposes will have become continuous in the students' experiences, that is, what the students were able to do before has become continuous with what they are able to do after the teaching in question.

The framework of organizing purposes is a tool for planning teaching so that conditions for continuity are met and, at the same time, for analyzing, along the way with the students, whether and how this is achieved in lessons. Thus, it specifies neither certain content nor certain teaching methods, although it does embody a view of science teaching in which it is considered important to provide students with meaningful and coherent activities at all times. This was a basic assumption shared by all the participants in the collaboration. The framework contributes with new ways of making explicit, during planning and assessment of science teaching, the successive, moment-by-moment steps through which students are supposed to progress towards the learning goals during a lesson or series of lessons. On the one hand, then, the collaboration contained a preconceived content decided by researchers, whereas, on the 
other hand, the content was one which ultimately aimed at increasing the teachers' authority and control over their professional practice. These are the two central ingredients of Richardson's (1992) agenda-setting dilemma.

The teachers were thus presented with, and first discussed, the framework through a Swedish translation of Johansson and Wickman's (2011) article. The article describes a physics lesson in which middle school students are engaged in activities for learning about friction, which is the ultimate purpose of the activity. In the same way, the authors identify a number of proximate purposes connected to different activities which the teacher has planned for the students. In one of these activities, the proximate purpose is that the students and the teacher talk about why we have tyres on wheels. The authors then demonstrate how it is possible to tell that the proximate purposes became ends-inview for students, by analyzing what they said and did and so showing that students were actually engaged with these purposes. For instance, they were quite able to talk with each other and with the teacher about the role of tyres, how they protect the streets from getting worn down and how cars without snow tyres slide on ice. Then, the authors show that although the proximate purposes worked as ends-in-view, they never became continuous with the ultimate purpose of learning about friction. For instance, the teacher did not help the students make distinctions between the different roles of tyres that they suggested, which to various degrees had to do with the concept of friction. In this way, the conceptual framework is laid out as a tool for planning and adjusting one's teaching to support learning progression by increasing the continuity between proximate and ultimate (or main) purposes.

\section{Analytic Approach}

The aim of the study was to examine the processes through which a new, research-based conceptual framework became integrated into science teachers' practice during collaboration with researchers. To that end, we used Clarke and Hollingsworth's (2002) interconnected model of teacher professional growth (Fig. 2), which assumes neither a certain perspective on knowledge and learning nor any particular experiences or sequence of experiences that teachers need to go through in order for it to count as change or growth. As a consequence, the model opens up for empirical investigation into the dynamics through which teachers change their knowledge, values, and practice (Justi and van Driel 2006; Witterholt et al. 2012).

The model recognizes four broad "change domains" and two basic processes mediating change between these domains, namely reflection and enactment (Fig. 2). It functions analytically by locating change in any of the domains and how that translates into change in the other domains. Relating to the present study, the external domain comprises changes brought by the researchers and the particular content conveyed to the teachers. Clarke and Hollingsworth stress that since teachers' professional practice is not exhausted by actual teaching in the classroom, the domain of practice includes all forms of professional experimentation. This is significant for the present study, since the external domain was concerned with change in the practice of planning and evaluation of teaching, not direct and specific change in classroom practice. The personal domain comprises change in teachers' knowledge and beliefs, and the domain of consequence change in what the teachers valued as salient outcomes from changes in the other three domains. Concerning the two mediating processes, reflection refers to deliberate consideration of something previously encountered, while enactment is distinguished from mere "acting" in that it 


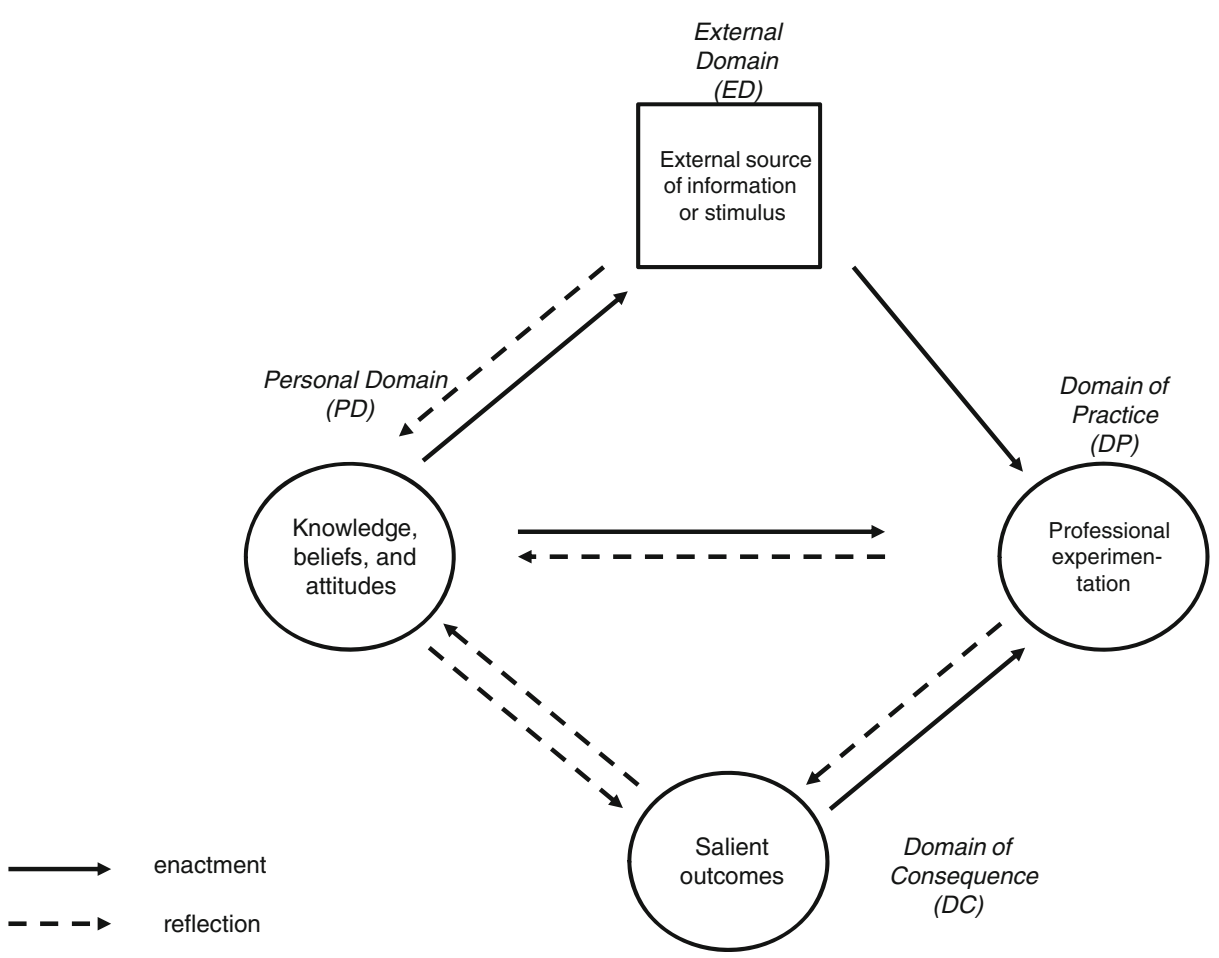

Fig. 2 The interconnected model of teacher professional growth. After Clarke and Hollingsworth (2002)

should include "the putting into action of a new idea or a new belief or a newly encountered practice" (Clarke and Hollingsworth 2002, p. 953).

The data analyzed in this study consist of the transcribed audio and video recordings of our joint meetings 1-7. The conversations were read through carefully, and all instances in which the new conceptual framework was used were located by looking for the specific concepts proximate purpose, main purpose, ultimate purpose, end-in-view, and continuity as well as derivatives such as proximate or ultimate goals or objectives. Having located all instances relating to the framework, we conducted two different analyses. First, we produced quantitative estimates of the frequency with which the concepts were employed, either by researchers or teachers. This quantitative measure of the actual use of the terms from the framework makes sense in view of the fact that what the teachers initially anticipated was precisely conceptual tools with which to adjust their teaching according to needs that they had identified already before the collaboration began. Thus, appropriating these new conceptual tools may be seen as one way for these teachers to acquire increased authority over their practice of planning and assessing their own teaching. It would, of course, also make sense to conduct more finegrained analyses of how the new framework was appropriated by the teachers. Such detailed analyses, paying attention not only to actual use of terms but also to other, more subtle signs of appropriation, will be presented elsewhere. We estimated both the total number of times that the concepts were used and the number of turns in which any of the concepts figured. Both estimates gave the result that the collaboration went through three distinct phases. Therefore, only the latter estimate is presented. Second, we analyzed each instance of handling the conceptual framework in relation to the interconnected model, deciding (1) whether a certain 
instance qualified as change or not and (2) which domain the change concerned. This analysis indicated characteristic change sequences in each of the three phases discerned through the quantitative estimates.

Criteria for analyses emerged as they proceeded (see Table 1). However, the analysis of the domain of practice requires some clarification. We analyzed how the conceptual framework effected change in teachers' practice of planning and assessing their teaching, not change in classroom practice. As we started to analyze the data, we realized that the change in the domain of practice seemed to occur in two ways, (a) through teachers actually employing the conceptual framework for planning new teaching and (b) through teachers employing it for talking about their previous teaching. On closer inspection, however, we decided to assign (b) rather to a change in the personal domain mediated by reflection on the external domain. This is because the context in which (b) occurred was almost exclusively one of clarifying the meaning of the framework's concepts. At the same time, we grant that these instances may also be counted as a special case of a change in the domain of practice, a kind of "professional experimentation" with the new concepts by applying them to familiar examples.

In summary, the results from the quantitative estimate revealed a pattern of distinct phases that the collaboration went through, whereas the qualitative analyses uncovered characteristic change sequences for each of the three phases. The two analyses thereby supplemented and corroborated each other, resulting in an account of the dynamics of teacher change in relation to the ways in which power and responsibilities were distributed between teachers and researchers during the collaboration.

\section{Results}

\section{Frequency of Use of Concepts}

The overall dynamics of the project may be divided into three phases based on the frequency with which teachers and researchers employed the concepts from the new conceptual framework (Fig. 3). The first phase consisted only of the first meeting in which the framework was introduced through an article that everyone had read beforehand. In this meeting, the frequency of use of the concepts of the framework was evenly distributed between teachers and researchers (Fig. 3). The second phase consisted of meetings 2-4. It was characterized by a marked drop in the use of the concepts, especially in meetings 2 and 3 (Fig. 3). During this

Table 1 Emergent criteria for deciding about change sequences in the analyzed conversations

\begin{tabular}{|c|c|}
\hline Relationship & Criteria \\
\hline ED-reflect-PD & $\begin{array}{l}\text { Teachers talk about the use or meaning of the framework and its concepts, compare the } \\
\text { framework with other, more familiar concepts or actions, or use the concepts to account for } \\
\text { their existing teaching }\end{array}$ \\
\hline PD-enact-DP & Teachers use the concepts for planning future teaching \\
\hline ED-enact-DP & $\begin{array}{l}\text { Teachers use the concepts for planning future teaching in close connection to the researchers } \\
\text { using them for the same purpose }\end{array}$ \\
\hline DP-reflect-DC & $\begin{array}{l}\text { Teachers talk about/comment on positive (or negative) effects of changes in the practice of } \\
\text { planning future teaching }\end{array}$ \\
\hline
\end{tabular}

$E D$ external domain, $P D$ personal domain, $D P$ domain of practice, $D C$ domain of consequence, reflect reflection, enact enactment 
phase, the planning of a new teaching unit on the chemistry of food ("Why can't we survive exclusively on French fries?") began. Thus, whereas in meeting 1 the teachers talked about the concepts in relation to already well-known units, meetings 2-4 required that they began to implement the framework for planning a new unit. Obviously, this was not an easy move to make and, consequently, the use of the concepts dropped markedly. The concomitant drop in the researchers' use of the framework reflects the approach to keep a low profile and let the teachers set the agenda. The last phase consisted of meetings 5-7. There was a significant increase in the use of the concepts of the framework in meeting 5 (Fig. 3). Moreover, this increase mainly concerned the researchers. It was not until meeting 7 that the teachers markedly increased their use of the concepts for planning the unit, indeed 2.5 times more frequently compared to meeting 6 . This was the largest increase in the teachers' use of the concepts of the framework between any two meetings during the project (Fig. 3).

Between the second and the third phase there occurred something that we, at the time, thought of as a minor "crisis" in the project. This will be described in more detail later. Suffice it to say here that after phase 2, the teachers did not appreciate the potential benefits of the framework in the same way as we, the researchers, did and they therefore wanted to allocate less time to the collaboration for the rest of the project. This "crisis" elicited a change in the way that we as researchers participated in the collaboration and reflected the way in which we tried to manage the dilemma of honoring the teachers' power over the content of the collaboration while, at the same time, stick to our intention of offering them a content (i.e., the framework) which we believed would support their professional practice in the way they expected from the collaboration. Thus, the reason for the increase in the researchers' use of the concepts beginning with meeting 5 reflects a conscious decision taken by the researchers, after meeting 4 but before meeting 5 , to increase our responsibility for actually implementing the framework in the teachers' practice of planning and assessing their teaching. Recall that meeting 4 was the last one before the first

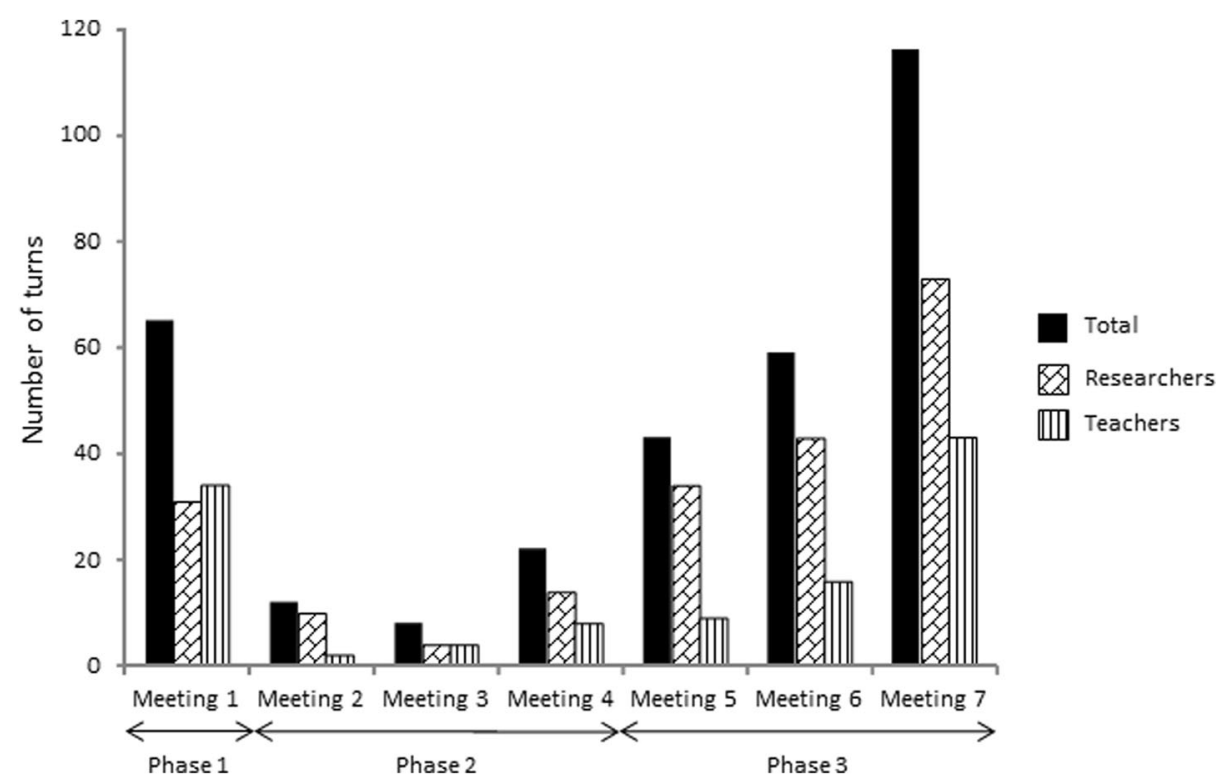

Fig. 3 Number of turns in which any of the concepts from the introduced framework occurred. Since each meeting was approximately of the same duration, the changes in frequency of using the concepts correspond fairly well to real changes between meetings in the extent to which the framework was used in the collaboration 
teacher (Ola) began to teach, whereas meetings 5-7 involved evaluating Ola's teaching and, concomitantly, planning the next cycle of the same unit.

In summary, there were marked changes in the frequency of the use of concepts from the framework during the collaboration. An initial intense use of the framework in meeting 1 dropped to almost nothing in the following three meetings, although a steady increase began after meeting 2. Moreover, the marked increase in the teachers' use of the concepts in meeting 7 was preceded by a corresponding increase in the researchers' use two meetings before, following a decision from the researchers to increase their responsibility for implementing the framework. Together, this indicates that both teachers and researchers changed their speech about teaching in the course of these meetings. The first change, between meeting 1 and 2, seems to be related to a change in the objectives of the meetings, moving from talking about the framework and earlier teaching to begin planning new teaching. The second change was related to a crisis in the project and to decisions taken by the researchers facing something similar to Richardson's (1992) agenda-setting dilemma. Next, we turn to an analysis of what these changes looked like in terms of the change dynamics of the collaboration. To make it easier for the reader to follow the conversations in excerpts $1-7$, teachers are marked $(\mathrm{t})$ and researchers $(\mathrm{r})$.

\section{Change Dynamics-Phase 1}

The first phase, which quantitatively was characterized by teachers and researchers using the new concepts in equal frequencies (Fig. 3), involved one distinct change sequence (Fig. 4). This sequence consisted of (a) change in teachers' knowledge mediated through reflection on the framework presented in the article (cf. Table 1) and (b) change in how the teachers talked about their planning of the new unit, mediated through enactment of the changed knowledge. The first part of the change sequence, change in knowledge through reflection on the framework, occurred both through discussions defining the new concepts and through the teachers "translating" their existing practice into the framework and its terminology. In the following example, Ola (t) and Erik (t) were using the concepts end-in-view (turns 2-3, 8) and ultimate goal (turn 8) to account for the common experience that the teacher's aims for lessons may not get through accurately to the students, resulting in the students lacking a sense of what the lesson is about:

Excerpt 1

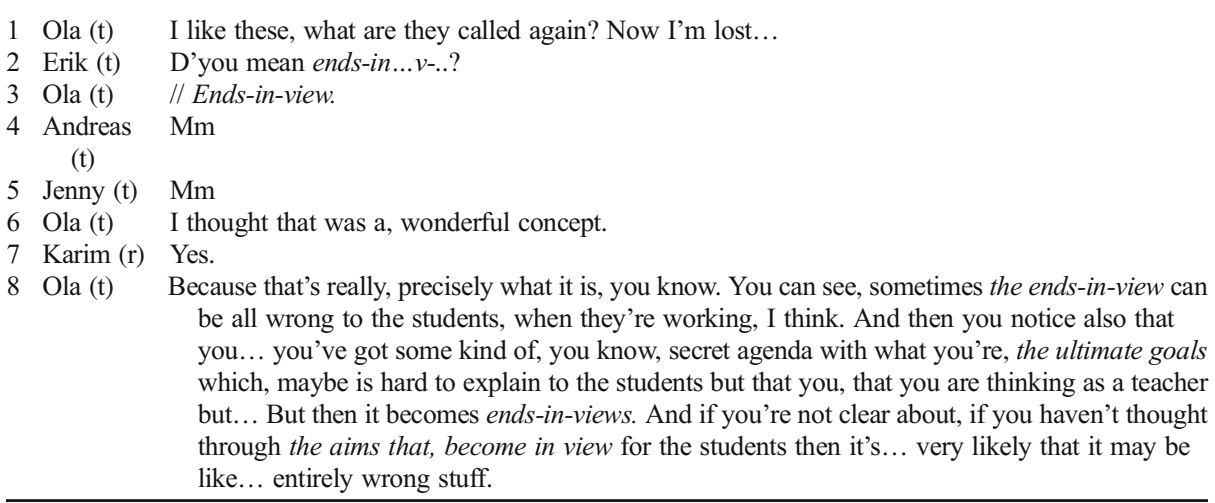


In this first meeting, the teachers also changed their practice of planning, which is illustrated in Fig. 4 as the second part of the change sequence, that is, change in the personal domain leading to change in the domain of practice, mediated through enactment. Thus, the teachers not only used the concepts in order to try them out against existing teaching practice but also began to use them for planning the new unit. This was especially easy to discern in meeting 1 , since there was a point when we jointly decided to leave the article and instead begin planning the new unit. This is illustrated in the following excerpt, in which Ola (t) and Erik (t) were discussing how to structure a laboratory on enzymes (breaking down starch to monosaccharides) which they considered might be part of the new unit and whether experiencing a shift in color demonstrating the presence of monosaccharides would help students learn about how enzymes work:

\section{Excerpt 2}

9 Erik And I don't know if... it's in itself more evident by, doing, a laboratory in which you first show that

(t) something doesn't have a color and then you add an enzyme and then, "well, now it's changed color, because now monosaccharides have formed" I mean... does that make things more lucid? They, realize that it changes color and all that but...

10 Ola (t) Right. You can't be sure that it's, sort of...

11 Erik No. If my ultimate purpose is that they should grasp, how enzymes work, then I'm not sure that I get (t) there...

12 Ola (t) No, no.

13 Erik $\ldots$ by making a solution change color.

14 Ola (t) No. So... how are you thinking about that, then?

In this excerpt, Erik (t) did not apply the concept ultimate purpose (turn 11) in order to talk about known practice, as Ola ( $\mathrm{t}$ ) did in excerpt 1 . Rather, he used it for planning new teaching - in this case how to organize a laboratory so that the message gets through to the students. Passages like these two support the proposed change sequence in Fig. 4, indicating that the teachers, through reflection on the article, had changed their knowledge about the framework even to the extent that they were able to occasionally use it as a tool for planning the new unit. However, there were only two more instances like the one in excerpt 2 during meeting 1 . Consequently, most of the initial planning of the unit during the first meeting was accomplished without the framework.

\section{Change Dynamics—Phase 2}

The second phase (meetings 2-4) was distinguished quantitatively through the marked drop in use of the concepts from the framework in planning the new unit. Apparently, despite the change in the teachers' knowledge about the framework from meeting 1 , they did not perceive it as a tool for conducting the concrete planning of the new unit. The researchers on their part,

Fig. 4 Change sequence observed in meeting 1 (phase 1). $E D=$ external domain, $P D=$ personal domain, $D P=$ domain of practice, broken arrow $=$ reflection, unbroken arrow $=$ enactment

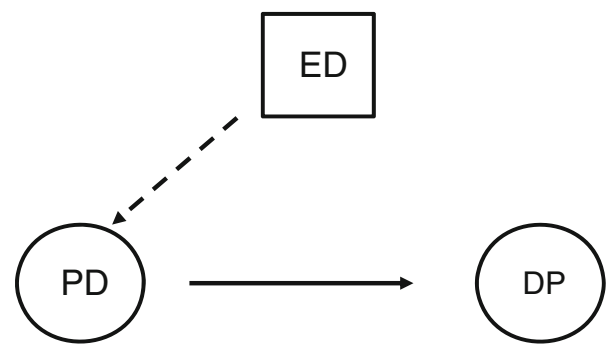


following their intent to preserve teachers' authority over their planning, were set not to press the framework on the teachers. Thus, we took active part in the discussions around the planning of the unit but made use of the concepts from the framework only occasionally, when it came naturally in the conversation.

The rare occasions on which the framework was nevertheless employed during phase 2 were characterized by a simple, yet distinct, change sequence consisting of change in the domain of practice (i.e., the practice of planning) through direct enactment of the framework (Fig. 5). This occurred in a characteristic manner, the change being regularly mediated through the researchers enacting the framework as a tool for planning, and the teachers more or less directly enacting it over again (Fig. 5). This is illustrated in the following excerpt in which a problem stated by Erik (t) and Ola (t) (turns 15-19) was restated by Karim (r) in terms of the framework (turn 20) after which Ola (t) almost directly employed a concept, ultimate purpose, from the framework (turn 24).

\section{Excerpt 3}

15 Erik ( $t$ ) I usually begin there too. And then we make some kind of concept map of it. But then when you begin to dig into it, there somewhere you lose, or at least the students, well but...

16 Ola (t) // Mm. The overall picture.

17 Erik (t) ..." what was, why am I sitting here reading about the kidney, I mean we were talking about an eraser that I threw", like, you know, "how did we end up here?", it becomes a rather...

18 Ola (t) Far fetched.

19 Erik (t) Yeah exactly, they're following the first time when you take up all the things that need to work. But then you often lose track of it.

20 Karim It's this thing with continuity, with purposes.

(r)

21 Ola (t) Yeah. And to create intermediate goals.

22 Erik (t) Yes.

23 Karim // Yes.

24 Ola ( $\mathrm{t}$ ) Cause if you have a, if you have an ultimate goal...

25 Erik $(\mathrm{t})$ // Yeah you need to be more clear...

26 Ola (t) ... that you can see like, "this is the big thing" kind of, but if you then say like this, "Ok, in order to be able to do certain things you need combustion and what systems work in order to, for..."

This kind of "imitation" did not occur each time the researchers employed the concepts from the framework. Also, on rare occasions, the teachers spontaneously used the concepts

Fig. 5 Change sequence observed during meetings $2-4$ (phase 2). ED = external domain, $D P=$ domain of practice, unbroken arrow $=$ enactment, $r=$ researchers, $t=$ teachers. $r+t$ indicates the observation that the sequence was characterized by researchers first employing the framework and the teachers doing the same thing in direct connection to the researchers
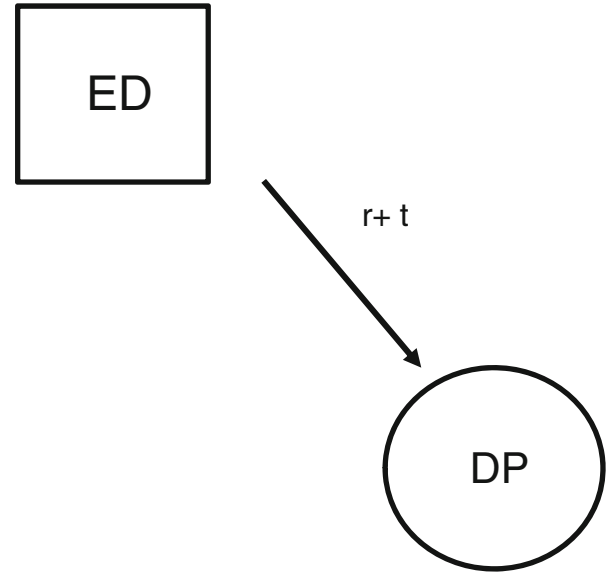
without any scaffolding from the researchers. However, the pattern was the primary change sequence during this phase. It stands out because of the rather long moments lacking the concepts altogether, interspersed with sequences in which a researcher mentioned a concept or made reference to the framework, followed by one of the teachers employing the concepts as well (Fig. 5).

What we have so far, then, is a first phase in which reflection on an introduced conceptual framework translated into some initial enactment of the framework in teachers' own planning, only to be followed by three meetings (phase 2) during which the framework was almost exclusively used by the researchers, sometimes followed by the teachers employing the concepts in response to this. In terms of Clarke and Hollingsworth's model, there were no obvious sustained change networks coming into being during these phases of the collaboration. It seems reasonable to assume that the teachers had appropriated the concepts fairly straightforwardly (as evident from phase 1) and that they therefore knew about them. So, there had been a change in the personal domain, even to the extent that the teachers could apply the concepts in planning their teaching (Fig. 4). On the other hand, this change in the domain of practice seemed to be transient and in need of continuous support in the form of the researchers introducing the concepts into the planning over and over again (Fig. 5).

\section{Change Dynamics - the Crisis}

As already mentioned, just before Ola's ( $t$ ) teaching was to begin after meeting 4, the researchers identified a crisis in the project. Although no formal analyses of the meetings were made during the collaboration, we noted that the change in the external domain in terms of the framework was contributing almost nothing to the teachers' planning of the unit, apart from isolated instances. Moreover, during meeting 4, we realized that the teachers did not perceive any positive consequences of the collaboration for their practice of planning teaching. This was manifested through the teachers expressing doubts about sacrificing as much time and effort in the project in the future as they had done up until now. Since the agreement for the collaboration was based on helping the teachers modify their teaching so that students learned more science during the units, and since we considered the conceptual framework to be our best shot, we became worried that the collaboration would end before the teachers had had the opportunity to appreciate the benefits of it. Rightly or not, we felt convinced that the framework had the capacity to empower the teachers and give them increased authority over their practice. At the same time, we did not want to press things and ignore the teachers' priorities which, at the moment, clearly did not include the framework. Since three of us also had backgrounds as teachers, we could easily appreciate the teachers' need to exclude anything that did not make things better or easier for them but rather took up precious and acutely lacking time. Thus, in retrospect, we were in the middle of something similar to Richardson's agendasetting dilemma.

After considerable thought and discussion between us researchers, we concluded that if we wanted to pursue our initial agenda, we needed to take responsibility for it ourselves, rather than putting all the responsibility for its implementation on the teachers. First, we took responsibility in the sense of accepting to do some of the 
necessary rough work of enacting the framework in actual teaching practice. Thus, we assumed increased responsibility for the realization of the framework by implementing it ourselves in the teachers' practice. Second, we took responsibility in the sense of exposing ourselves to potential critique concerning the consequences of using the new framework by getting involved in the teachers' practice. This means that we also assumed responsibility for the outcome of the teaching resulting from implementing the framework. At the time, we conceptualized this changed assumption of responsibility in terms of what we, the researchers, risked in the project compared to the teachers. Thus, we talked about our initial, low-profile engagement as being also one of low risk, in that we did not put anything at stake in the collaboration. We offered a solution to the teachers, but we did not invest much of our credibility in its implementation. Moreover, we realized that we might possibly even increase the risk that the teachers needed to take if they were to be responsible for carrying through the implementation of the framework in their practice themselves. This is because it would be those new to the framework who took responsibility for implementing it in actual planning, not those who knew the framework best. Now, we wanted to change that. Thus, we wanted to share both the burden of actually putting the framework to work in action and the risk of failure when doing that.

Obviously, although we decided to increase our responsibility for the collaboration, this measure nevertheless meant a step back from our intent to distribute power over the content of the collaboration equally between teachers and researchers. Instead, should the teachers agree to our suggestion, we would much more actively than during the four initial meetings actually impose the framework on the teachers' practice.

The researchers' new role in the collaboration was intended to begin with the first meeting after Ola $(\mathrm{t})$ had finished his teaching of the new unit (meeting 5). But already before meeting 5 , this increased responsibility manifested itself in that we promised the teachers (1) to provide a concrete and productive analysis of Ola's ( $t$ ) teaching based on the framework and (2) that this analysis would have clear, positive consequences for the next teaching cycle, that is, Jenny's (t) teaching after meeting 7. Since this was what the teachers had hoped from the collaboration from the beginning, they responded positively and agreed to set off time for three more meetings, which would be used to analyze Ola's (t) teaching of the unit and plan the same unit for Jenny's ( $\mathrm{t}$ ) class.

\section{Change Dynamics_-Phase 3}

As a consequence of the decision to concretely implement the conceptual framework in the teachers' practice, during the first half of meeting 5, we presented a thorough analysis of Ola's (t) teaching and made concrete suggestions for how to change the teaching of the unit for cycle 2. Both the analysis and the subsequent suggestions for how to change teaching are built explicitly on the framework and its concepts, hence the marked increase in the researchers' use of the concepts of the framework during this meeting, initiating phase 3 of the collaboration (Fig. 3).

Although the researchers had made use of the framework for making suggestions for teaching also during phases 1 and 2, an important difference in phase 3 was the explicit 
emphasis on actual consequences of making the changes suggested from the analysis of Ola's

(t) teaching. Excerpt 4 illustrates how this was done:

\section{Excerpt 4}

27 P-O (r) So... No but this is what we see happening. No, wait, is there something at the end? No but that's what's happening in the first lesson, or what you're doing, in the first lesson. So what we see, then, is... that there are proximate purposes. And, here we've numbered three: "Why can't we survive exclusively on French fries?", "What nutrients do we need?", and...

28 Karim "What do French fries contain?"

$(\mathrm{r})$

29 P-O (r) "What do French fries contain?"

30 Ola $(\mathrm{t}) \quad \mathrm{Mm}$

31 P-O (r) And... then it's like... the main purposes that are done are "what nutrients does food contain?", "how do we find out foo-, do you find out what, nutrients food contains?" And, "what nutrients food contains", well I've enumerated which ones are treated here and how they're labeled. And, "find out what nutrients food contains", what you do here, mainly, is to use tables of content, either via the national food administration...

32 Ola (t) // Mm

33 P-O (r) … or via a bag of... French fries

34 Ola (t) Mm

35 P-O (r) So... And, we're thinking, then, that this, proximate purpose number two, I mean "what nutrients do we need?", that's treated, then, it can, that one the students are engaged talking about, they leave suggestions, simply. And, these proximate purposes... one and three, we claim that they're harder to see, and it... And that's what, and with that we mean that it's harder to see, what the students actually understand of them. So, our suggestion is really about making it more obvious, that, so that it becomes, that this continuity becomes visible right there in the classroom, so that you see it.

As can be seen, the concept proximate purpose was used to distinguish what it is that is going on during the lesson, "what you're doing," as P-O (r) put it (turn 27). Furthermore, the purposes were laid down as concrete formulations, much in the way the researchers had hoped they would do in Ola's (t) planning of the unit. Then, the distinction between the three proximate purposes was used to make a claim about which ones seemed to work and not to (turn 35). Finally, P-O (r) moved the analysis into a first suggestion for how to meliorate this situation, so that purposes 1 and 3 would also be visible as actions in the classroom. In doing so, he used another concept from the framework, namely the need to establish continuity between purposes (turn 35).

The teachers did not respond to the researchers' changed approach by increasing their own use of the concepts from the framework during meeting 5, compared to meeting 4 (Fig. 3). However, something else happened, which we interpret as the beginning of a new change sequence (Fig. 6). Thus, the teachers responded to the suggestions made by the researchers by explicitly appreciating the expected positive consequences for classroom practice. In Fig. 6, this is indicated as a change in the domain of consequences mediated through reflection on a change in the domain of practice, which was in turn mediated by the researchers themselves enacting a change in the external domain (i.e., we did some of the assessment and planning that should eventually be done by the teachers). Excerpt 5 gives an example of how the teachers responded by noting such consequences. Before the excerpt, the researchers had presented the idea of modifying one of the main purposes, namely "What nutrients does food contain?" into a proximate purpose that could become an end-in-view for the students and, thus, become visible as actions in the classroom. The suggestion was to make the students bring packages of food from home, ask them to read from the lists of content, and together with the teacher order what came out of this into chemically appropriate categories (such as carbohydrates, fats, and proteins, and subsequently different kinds of these categories): 
Fig. 6 Change sequence observed during meeting 5 (first meeting of phase 3$) . E D=$ external domain, $D P=$ domain of practice, $D C=$ domain of consequence, broken arrow $=$ reflection, unbroken arrow $=$ enactment. Unlike Clarke and Hollingsworth's (2002) original model, the researchers $(r)$ were the ones enacting change in the domain of practice. The teachers ( $t$ ) then reflected on that change by changing what they perceived as salient outcomes of the framework

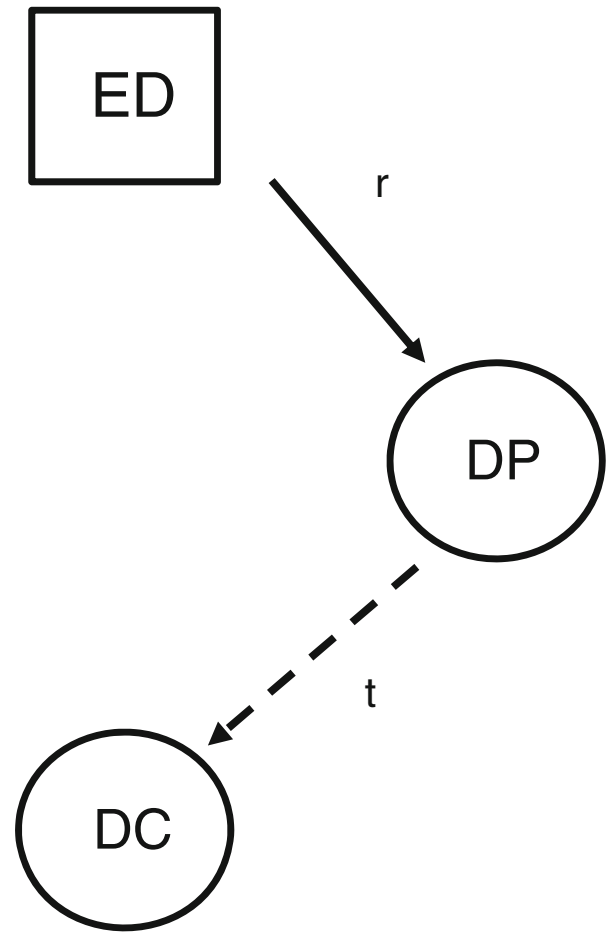

\section{Excerpt 5}

36 P-O Yeah we thought that we could include that. And I'm just going to say, the other thing that we were

(r) thinking with that, it's that you would, be able to ask them, then, if you've got the table of content for the French fries and the tables of content for the other food stuffs, then you could sort out together: "what do French fries contain and what do French fries not contain, and what do other food stuffs contain more and what do they contain less?" And then it's, can, and what makes this into an end-in-view [in English], so to speak, end-in-view [in Swedish], it's that the students are able to do this. It's something that they can actively have...

37 Ola (t) Join in.

38 P-O Join in.

(r)

39 Ola (t) Instead of it becoming only a discussion between me and a few students.

40 P-O Yeah exactly. So they can, they're able to do this and become, be competent in it sort of. And at the

(r) same time you're doing something which is, which is in fact probably the most important way for

41 Erik Yeah people to, find out what food contains is to read a table of content.

(t)

42 P-O So that's our...

(r)

43 Ola (t) That's terrific!

As can be seen, Ola ( $t$ ) addressed the consequences of making this change three times only during this short conversation. First, he interjected with "join in" (turn 37), explicitly showing that he acknowledged the difference between how it was done the first time around and how we suggested it to be done instead. This became even more obvious as he added: "Instead of it becoming only a discussion between me and a few students" (turn 39), explicitly acknowledging 
Fig. 7 Change sequence observed during meetings 6 and 7. It may be considered a combination of the change sequence from Figs. 4 and 6. $E D=$ external domain, $P D=$ personal domain, $D P=$ domain of practice, $D C=$ domain of consequence, broken arrow $=$ reflection, unbroken arrow $=$ enactment

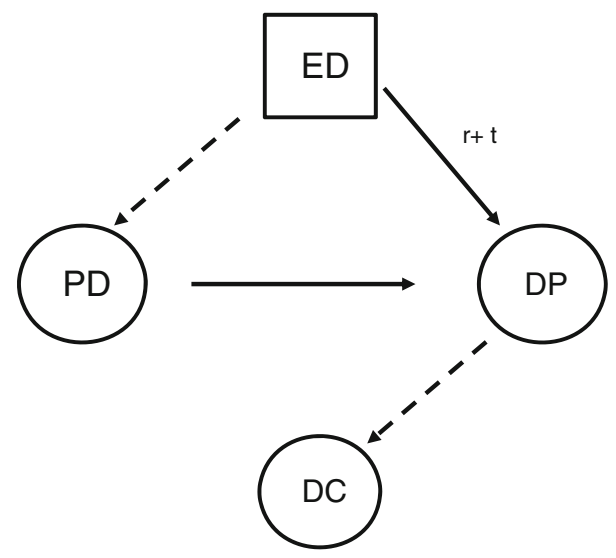

a positive consequence compared to what had happened in his first lesson. Finally, he anticipated the consequences through the aesthetic judgment: "That's terrific" (turn 43).

The pattern illustrated through excerpt 5 and the change sequence in Fig. 6, that is, the teachers acknowledging salient outcomes of using the framework for analyzing and modifying teaching, was the predominant one found in meeting 5 . It continued also in meeting 6 , but here the initial pattern from meeting 3 became visible again. That is, there was a certain amount of talk concerning the meaning of the concepts from the framework similar to what occurred during our first meeting (phase 1). Sometimes, these two change sequences were more or less tied together (Fig. 7).

Finally, meeting 7 was characterized by a marked increase in the teachers' use of the concepts of the framework (Fig. 3). This was not accompanied by any new change sequence, but a similar pattern to that in meeting 6 (Fig. 7) dominated. Instead, the change was visible in that the teachers used the concepts between themselves to a much greater extent than before, making the change sequence from Fig. 5 less significant for the first time. Excerpt 6 illustrates this beginning autonomy concerning the teachers' use of the concepts. The problem dealt with was what significance a laboratory about the enzyme lactose could have for learning about enzymes.

\section{Excerpt 6}

44 Ola (t) Ok, wait. The main purpose, that's to try out their tools.

45 Erik (t) Mm

46 Ola (t) Right? But, and that's both... uhm... to be able to draw conclusions.

47 Erik (t) But their task is to test if that pill works.

48 Ola (t) Yeah.

49 Jenny (t) One proximate purpose has got to be to look at the enzymes, because you've talked about the enzymes before and looked at that starch solution.

50 Ola $(\mathrm{t}) \quad \mathrm{Mm}$

51 Jenny (t) Whether it's changed when you've spat in it, "Ok, there is something which changes". And then it was, you talked about... This was in order to test if, well whether milk intolerants, if they've

52 Ola (t) Mm got this enzyme or not.

53 Karim (r) If it works, you mean?

54 Ola (t) Yes.

55 Jenny (t) If it works, and how it works. 
56 Ola (t) Yes. Yes. Yes. And... that's their task or what you should call it. I know...

57 Jenny (t) But isn't that a proximate purpose with the entire thing, to check whether the enzyme works. Couldn't that be something?

58 Ola (t) "Does the medicine work?"

59 Jenny (t) //Yeah, "does the medicine work?"

60 Erik (t) //Mm

61 Andreas $/ / \mathrm{Mm}$

(t)

62 Ola (t) ... is you know sort of... uhm, end-in-view.

Before meeting 7, we cannot find this kind of prolonged discussions in which the teachers made use of the concepts of the framework for planning the unit. In that sense, it was the most obvious change that the teachers went through during the entire project, and it showed itself both quantitatively (Fig. 3) and qualitatively (excerpt 6).

\section{What Happened Next?}

The results presented here constitute an analysis of the processes through which a group of teachers changed their knowledge and practice of planning during teacher-researcher collaboration. The changes involved the appropriation of a conceptual framework which was developed to give teachers' increased means to plan their teaching according to perceived purposes and thus allow them increased authority over their professional practice. The primary evidence for increased authority are, of course, the increased use of the framework (as revealed through the quantitative estimates) together with the proposed change sequences and the excerpts presented. However, other more anecdotal evidence also exists, which may be of supplementary interest. Therefore, we here briefly present what happened after meeting 7.

To begin with, we have extensive documentation of Jenny's ( $t$ ) own enthusiasm over how the unit worked out as a result of the modifications made during meetings 5-7 (manuscript). And as we began planning the third unit, after Jenny's teaching, the teachers continued to make use of the framework. It may seem as if the four teachers appropriated the new conceptual framework to different degrees. To some extent, this may be true, considering that Ola $(t)$ and Jenny $(t)$ were the only ones who, within the realms of the data presented here, actually experienced the framework as part of their own teaching. Eric (t) knew from the beginning that he would not plan a unit of his own during the project due to his upcoming parental leave. As far as the data presented here are concerned, the same goes for Andreas ( $\mathrm{t}$ ) who, moreover, was going to teach an entirely different unit from the one being the focus in the discussions presented here.

But the consequences also went beyond the boundaries of the project as such. One semester later, Ola (t) spontaneously introduced the ideas from the framework as a tool for working with science teaching with his colleagues from grades 1 to 6 . Moreover, the teachers have presented the outcomes of the project to other staff in the school, again, entirely without us knowing it in advance. Finally, Ola ( $t$ ) and Jenny $(t)$ have also presented the framework to teacher educators at our department as well as to colleagues in the district during professional development conferences.

\section{Summary of Results}

In this project, an initial change in the external domain, in the shape of a new conceptual framework, was mediated through reflection into a change in the personal domain (i.e., 
changed knowledge). Moreover, this latter change was almost immediately mediated into change in the domain of practice, through enactment of the newly acquired knowledge (Fig. 4). All this happened during the initial meeting making up phase 1 of the collaboration (Fig. 3). In phase 2, on the other hand, the initial integration of the framework into the teachers' practice was no longer evident (Fig. 3) and was only occasionally accomplished through direct enactment of the external domain into the domain of practice through imitation of what the researchers did (Fig. 5). This led to a crisis during the fourth meeting, characterized by different agendas being pursued by teachers and researchers, respectively, thus reflecting aspects of Richardson's (1992) agenda-setting dilemma. Then, a particular kind of response to this crisis, namely that the researchers insisted on the framework being part of the content of the collaboration and, simultaneously, assumed some of the responsibilities traditionally laid upon teachers, marked the transition of the collaboration into phase 3 . In terms of change dynamics, the result of this change was something which may not be anticipated from Clarke and Hollingsworth's original model, namely that a new change in the external domain, this time in the researchers and not the framework, was enacted by the external domain itself into a change in the domain of practice (Fig. 6). Moreover, this imposed change in the domain of practice seems to have led, through reflection, to a subsequent change in the domain of consequence (Fig. 6). Finally, what seems to be a merging of several earlier change sequences during meeting 6 (Fig. 7) eventually ended in the teachers appropriating the framework as a tool for planning, beginning with meeting 7 , and also recognizing that the framework allowed them increased authority over their professional practice, in terms of having the conceptual means to implement that which they intended with their science teaching.

\section{Discussion}

In this study, we presented a detailed analysis of teacher change during collaboration between science teachers and science education researchers by focusing on the process of incorporation of new knowledge, i.e., a new conceptual framework, into science teacher practice. We found that the researchers' increased assumption of responsibility for implementing the conceptual framework contributed to change in teachers' practice of planning. This finding may be interpreted in two complementary ways, namely in terms of (1) the researchers providing the teachers with concrete examples of how the framework might be used and the teachers perceiving salient outcomes of this concrete work and (2) the researchers sharing some of the risks associated with innovation in teaching practice. These two angles to the findings are elaborated on below.

\section{Researcher Responsibility and Salient Outcomes}

Teacher change seems to have come about in part through the combination of the researchers actively incorporating the framework in the teachers' practice and the teachers noticing salient outcomes of the implementation of the framework. Thus, the results indicate that (a) teachers need to recognize salient outcomes of the new knowledge and (b) that such recognition may be facilitated if the researchers take increased responsibility for implementing the new knowledge in teaching practice themselves. The teachers quickly and seemingly effortlessly appropriated and also applied the new conceptual framework (Fig. 4), but this change did not persist of itself 
but needed scaffolding from the participating researchers (Fig. 5). For it to become established required the researchers, as the sources and guarantors of the knowledge, to take responsibility for applying the knowledge themselves in the very practice that was expected to change, namely that of teacher planning (Fig. 6). This may have been a necessary part of the teachers' change process, experiencing the process of analyzing and modifying teaching as the new framework was explicitly applied by the researchers. This explicitness may have allowed the teachers to more concretely visualize the use of the framework within their own context. Moreover, it seems as if the dynamics of change were that the teachers appreciated that the changed practice had certain salient outcomes connected to it (Fig. 6). This recognition of outcomes may have helped the teachers understand the potential benefits of the framework. This elicited renewed interest in talking about the concepts, as well as, eventually, enabling the teachers to apply the framework as a tool for planning their own teaching (Fig. 7).

In terms of the interconnected model, our initial change sequence resembles the two initial stages of what Clarke and Hollingsworth (2002, p. 960) referred to as the "naïve linear model" of teacher professional growth, in which change in the external domain effects change in the personal domain, followed by subsequent change in the domain of practice (Fig. 4). Similar sequences, although as part of more complex networks than what we have observed, were also demonstrated by Justi and van Driel (2006). Subsequent changes resemble the beginnings of what Clarke and Hollingsworth referred to as the first cycle of action research, except that in our case the initial changes to the practice were entirely accomplished by the researchers, not the teachers, whereas it was the teachers who, then, reflected on changed salient outcomes (Fig. 6). This is potentially significant, since Clarke and Hollingsworth (2002) originally made a distinction between two types of domains in the model. Thus, they considered the domain of practice to constitute part of the teacher's personal world together with the personal domain and the domain of consequence, whereas the external domain was located outside of the teachers' personal world. Our results, however, indicate that the interconnected model may need to more explicitly recognize the different possibilities of joint collaboration during science teacher professional development, even to the extent that the representatives of the external domain, in this case the researchers, themselves enact change in the domain of practice.

\section{Researcher Responsibility and Alleviation of Risk}

A complementary way of conceiving of our increased assumption of responsibility is that the teachers were relieved from some of the risks connected to change in teaching practice. There is no doubt that teachers take considerable risks as they engage in the implementation of innovations in their practice. Such risks involve failure on a personal as well as public level, for instance frustration in the face of unrealized ambitions, loss of laboriously built-up relations to one's own students, lack of gain in terms of student achievement, increased workload, nonacceptance of the innovation from school management, students, or parents, and reduced professional status (Gilbert 1992; Olson 2002; Iredale et al. 2013). Because the researchers in this study became the ones implementing the framework into the teaching plans, the teachers did not have to take the whole blame for possible failure, neither personally nor publicly. So although Ola and Jenny retained the formal responsibility for providing good teaching to the students, and thus still stood the greatest risk of failure, part of it was distributed to the researchers. In addition, there is an interesting possible connection to the teachers' anticipation of salient outcomes from the changes suggested by the researchers. Because the teachers were 
able to appreciate these outcomes in advance, the perceived risk connected to the changes was lowered. Here, then, the alleviation of risk had to do more with increased opportunities for the teachers to assess outcomes of the suggested changes.

At the same time, this alleviation of the risks came at a cost, namely that the distribution of power over the content of the collaboration was temporarily tilted towards the researchers. Possibly, an unintended consequence of the strive to distribute power equally during this kind of collaboration may be that researchers, by backing from their traditional expert role and giving up their power over the content, at the same time assume less responsibility and take less risk in the collaboration, while teachers assume more of both. Moreover, this may be especially problematic if the researchers are still feeding the collaboration with knowledge and ideas, which the teachers assume responsibility for implementing, at risk, into their practice.

\section{Managing Richardson's Dilemma}

Our results suggest that there may be more to Richardson's (1992) agenda-setting dilemma than the distribution of power in this kind of collaborations: in addition to asking who owns the content of science teacher-science education researcher collaborations, we may also need to ask who assumes what responsibilities for bringing about the intended changes during the collaboration (i.e., responsibility in the first sense described above) and who becomes subjected to the risks connected to these changes (i.e., responsibility in the second sense described above). It may simply make sense that those who actually make the claims about the virtues of certain content of the collaboration, i.e., change in the external domain, perhaps should also be those who initially take the burden of carrying the ideas through and assume the risk of failure and critique for their implementation. Thus, we may ask if there is a risk that efforts to increase equality concerning power over the content of TPD may also bring with them increased inequality when it comes to other aspects of the collaboration, such as which category of participants is the one facing the greatest risk of failure, critique, and increased workload as a consequence of the collaboration.

We do not suggest that we, as researchers, managed Richardson's dilemma by avoiding exercising power and, instead, assumed responsibility and assumed increased workload and risks. From the perspective of power over the content, it is clear that it was we who assumed the power, explicitly setting the agenda by sticking to the initial conceptual framework. Likewise, we do not suggest that our increased assumption of responsibility distributed the risks associated with introducing the framework to teaching practice evenly between teachers and researchers.

In fact, the "colonization" by the researchers of the domain of practice (Fig. 6), following the crisis after meeting 4, may at first sight be considered as a rather blunt way of setting the agenda old-fashion style, the faculty experts knowing entirely what the teachers/learners need, and also wielding their age-old power in order to make it happen. And it is, of course, true that the balance of power within the collaboration changed as a result of our decision. After all, the essence of the agenda-setting dilemma is precisely that two competing purposes, to provide externally produced expert knowledge in order to increase teacher authority over their teaching and, at the same time, allow teachers power over the content of the collaboration, are inherently difficult to reconcile. So the decision meant that we, and not the teachers nor the team, temporarily set the agenda and, thus, exercised our power as researchers more than earlier during the collaboration. At the same time, we interpret our changed approach, that is, to increase our responsibility for the implementation of the framework, and the course of events following it as the single event during the collaboration which meant the most for 
increasing the participating teachers' authority over their practice, in line with their initial expectations for the collaboration.

Another aspect made visible from our results concerns more directly Richardson's initial question of ownership over the content in TPD. Perhaps, we need to recognize that the content itself changes in the course of the collaboration, as a result of changes in the domain of practice and the domain of consequence. After all, one may argue that the content of our collaboration was not really the same in phases 1 and 2 (meetings 1-4) as it was in phase 3 (meetings 5-7). True, we insisted on continuing with the same conceptual framework all along. But one difference between the first two phases and the third one is that in the latter, potential and actual consequences of the framework became part of the content of the discussions. Put another way, the initial content changed as a result of changing the practice, which was what we researchers took care of in the first part of phase 3 by assuming increased responsibility for its implementation. The researchers pressing on with the conceptual framework without this concomitant change in practice would indeed have been to deprive the teachers of real power. Pressing the framework through changed practice, on the other hand, meant that the content became different than before. In a sense, then, the teachers may even be said to have had significant influence over the content of the collaboration, after all. By indirectly forcing us, the researchers, to put the conceptual framework to use in the very practice that we claimed it would improve, the teachers got a content that was closer and more relevant to their perceived needs.

Considering this course of events, we may draw certain conclusions concerning how new content may be fruitfully introduced in this kind of collaboration. In particular, it seems reasonable that the work that needed to be done after the "crisis" could be made part of the collaboration in earlier phases. For instance, judging from our results, it seems reasonable that a new framework should initially be implemented in a well-known unit, instead of trying to make it work in entirely new settings. In that way, the unit may be run and evaluated so as to provide opportunities for teachers to perceive salient outcomes, positive or negative, of the changed practice. Moreover, this implementation should be made to a large extent by those introducing the new content, for instance the researchers in the collaboration. It is less clear what to make of the initial, joint reading of the scientific paper outlining the framework during meeting 1. But it seems obvious that, at least, it provided a common understanding and vocabulary that was recruited during the third phase of the collaboration. In terms of the interconnected model by Clarke and Hollingsworth (2002), we may frame these suggestions more systematically: (1) the external domain needs to be enacted in the domain of practice not only by teachers but also by those offering the new content, and (2) care should be taken to reflect on salient outcomes from the change in the domain of practice, so as to effect change also in the domain of consequence.

Reasonably, what has been said above may depend in part on the nature of content introduced in the collaboration. The content in the present collaboration was a generic framework for choosing and ordering science content during lessons or sequences of lessons. Other, more specific content, for instance ready-made curricula or teaching units, may offer greater challenges concerning how to introduce them in ways that empower teachers. At the same time, it may still be important that teachers are not left with the entire responsibility for implementing the changes, even in TPD programs introducing more specific ideas or methods of how to teach science.

\section{Methodological Considerations}

The results presented in this study need to be considered in light of this being a single case study of a small-scale collaboration. Such studies lend themselves well to the kind of detailed 
study of mechanisms presented here (Maxwell 2004). In that respect, our results may be considered as valid exemplars of plausible mechanisms and courses of events that may apply in this kind of settings. At the same time, studies such as this one should invite caution concerning extrapolation to other settings. Indeed, as we have tried to emphasize above, the conclusions from the study need to be considered in relation to the specifics of the collaboration. And of course, to the extent that the suggestions presented here should become part of large-scale TPD programs, they should be tried out and corroborated in further studies with varying conditions. With these limitations in mind, however, our results may have some implications also for larger-scale collaborations, involving more teachers and schools as well as wider and more complex contents (for instance entire new curricula that are being implemented). The requirement should be, at least, that the collaboration includes the two "ingredients" of Richardson's (1992) agenda-setting dilemma, that is, (1) experts introducing certain content that is considered central to the TPD and (2) an emancipatory ambition, meaning that the collaboration should result in empowerment of the participating teachers, both concerning teaching practice and TPD. For collaborations lacking one of the two requirements of the dilemma, on the other hand, our results should have no actual meaning. Either there is no expert-privileged content in the first place, for instance because such knowledge is produced locally and collectively along the collaboration, as in professional learning communities (c.f. O'Donnell-Allen 2004), or shared ownership over the collaboration is not on the table, which may be true of certain top-down efforts to implement particular teaching strategies (c.f. Bartholomew and Sandholtz 2009; Loughran and Ingvarson 1993).

It is important for the interpretation of our results that they were produced through a combination of two separate analyses, one quantitative estimate and one qualitative analysis of mechanisms, which supported each other in significant ways. In particular, the quantitatively weak use of the concepts of the framework during the two first phases corresponded to two characteristic change sequences which mirrored this use. Similarly, the increase in the use of the concepts of the framework in the third phase of the collaboration corresponded to two other change sequences which made this increase reasonable. This supplementary role of the two analyses adds to the credibility of our results.

\section{Conclusion}

There seem indeed to be more aspects to balance teacher-researcher collaboration than the distribution of power over the content of the TPD that was initially suggested by Richardson (1992). In this study, we demonstrated the need to balance also the distribution of responsibility, both in terms of implementing new content in teacher practice and in terms of the exposure to the risks connected to that implementation. In particular, our study suggests that maximizing teacher control over the content may come at too high a cost in terms of teacher responsibility for implementing that content, possibly hindering long-term teacher empowerment as a consequence of the collaboration. Instead, it seems important to emphasize that researchers take responsibility for implementing the content that they introduce, even if this means momentarily decreasing teacher control over the content. However, contrary to what was the case in this study, it seems reasonable that the differential distribution of power and responsibility be explicitly negotiated both at the beginning of a new collaboration and as the collaboration proceeds. Further studies could shed light on the ways in which such explicit negotiation may help balance these two aspects in fruitful ways. 
Acknowledgements This study is part of the project TALES, funded by the Swedish Research Council (VRUVK: 2010-5171). We acknowledge the contributions of all participants in the collaboration: the teachers, the principal, and the project members Åke Ingerman, Clas Olander, Anette Olin, and Marlene Sjöberg, who have contributed in discussions and development of ideas during the project. The teachers have agreed to appear in the text with their correct names.

Open Access This article is distributed under the terms of the Creative Commons Attribution 4.0 International License (http://creativecommons.org/licenses/by/4.0/), which permits unrestricted use, distribution, and reproduction in any medium, provided you give appropriate credit to the original author(s) and the source, provide a link to the Creative Commons license, and indicate if changes were made.

\section{References}

Bartholomew, S. S., \& Sandholtz, J. H. (2009). Competing views of teaching in a school-university partnership. Teaching and Teacher Education, 25(1), 155-165.

Butler, D. L., Lauscher, H. N., Jarvis-Selinger, S., \& Beckingham, B. (2004). Collaboration and self-regulation in teachers' professional development. Teaching \& Teacher Education, 20(5), 435-455.

Callahan, J. L., \& Martin, D. (2007). The spectrum of school-university partnerships: a typology of organizational learning systems. Teaching and Teacher Education, 23(2), 136-145.

Clark, C., Moss, P. A., Goering, S., Herter, R. J., Lamar, B., Leonard, D., et al. (1996). Collaboration as dialogue: teachers and researchers engaged in conversation and professional development. American Educational Research Journal, 33(1), 193-231.

Clarke, D., \& Hollingsworth, H. (2002). Elaborating a model of teacher professional growth. Teaching and Teacher Education, 18(8), 947-967.

Cuban, L. (1992). Managing dilemmas while building professional communities. Educational Researcher, 21(1), 4-11.

DiGisi, L., Nix, A., Daniels, K., Kramer, L., \& Cyr, S. (1999). Embracing the complexity of inclusive science classrooms: professional development through collaboration. Research in Science Education, 29(2), 247268. doi:10.1007/bf02461771.

Erickson, G., Brandes, G. M., Michel, I., \& Mitchell, J. (2005). Collaborative teacher learning: findings from two professional development projects. Teaching and Teacher Education, 21(7), 787-798.

Gilbert, J. (1992). Risk-taking and teachers' professional development: the case of satellite remote sensing in science education. Research in Science Education, 22(1), 157-162. doi:10.1007/bf02356891.

Hamza, K. M. (2013). Distractions in the school science laboratory. Research in Science Education, 43(4), 14771499. doi:10.1007/s11165-012-9316-z.

Hamza, K. M., \& Wickman, P.-O. (2009). Beyond explanations: What else do students need to understand science? Science Education, 93(6), 1026-1049.

Hardy, I., \& Melville, W. (2013). Contesting continuing professional development: reflections from England. Teachers and Teaching, 19(3), 311-325. doi:10.1080/13540602.2012.754162.

Iredale, A., Orr, K., Bailey, W., \& Wormald, J. (2013). Confidence, risk, and the journey into praxis: work-based learning and teacher development. Journal of Education for Teaching, 39(2), 197-208. doi:10.1080 /02607476.2013.765192.

Jakobson, B., \& Wickman, P.-O. (2007). The roles of aesthetic experience in elementary school science. Research in Science Education, 38(1), 45-65.

Johansson, A.-M., \& Wickman, P.-O. (2011). A pragmatist approach to learning progressions. In B. Hudson, \& M. A. Meyer (Eds.), Beyond Fragmentation: Didactics, Learning, and Teaching (pp. 47-59). Leverkusen, Germany: Barbara Budrich Publishers.

Justi, R., \& van Driel, J. (2006). The use of the interconnected model of teacher professional growth for understanding the development of science teachers' knowledge on models and modelling. Teaching \& Teacher Education, 22(4), 437-450.

Lidar, M., Lundqvist, E., \& Östman, L. (2006). Teaching and learning in the science classroom: the interplay between teachers' epistemological moves and students' practical epistemology. Science Education, 90(1), $148-163$.

Loughran, J., \& Ingvarson, L. (1993). Science teachers' views of professional development. Research in Science Education, 23(1), 174-182. doi:10.1007/bf02357058.

Lundegård, I., \& Wickman, P.-O. (2007). Conflicts of interest: An indispensable element of education for sustainable development. Environmental Education Research, 13(1), 1-15.

Lundqvist, E., Almqvist, J., \& Östman, L. (2009). Epistemological norms and companion meanings in science classroom communication. Science Education, 93(5), 859-874. 
Mansour, N., El-Deghaidy, H., Alshamrani, S., \& Aldahmash, A. (2014). Rethinking the theory and practice of continuing professional development: science teachers' perspectives. Research in Science Education, 44(6), 949-973. doi:10.1007/s11165-014-9409-y.

Maxwell, J. A. (2004). Causal explanation, qualitative research, and scientific inquiry in education. Educational Researcher, 33(2), 3-11.

McNicholl, J. (2013). Relational agency and teacher development: a CHAT analysis of a collaborative professional inquiry project with biology teachers. European Journal of Teacher Education, 36(2), 218-232. doi:10.1080/02619768.2012.686992.

O’Donnell-Allen, C. (2004). Raising our voices: transformative discourse in a teacher research group. English Education, 37(1), 50-74.

Olson, J. (2002). Systemic change/teacher tradition: legends of reform continue. Journal of Curriculum Studies, 34(2), 129-137. doi:10.1080/00220270110085697.

Orlander, A. A., \& Wickman, P.-O. (2011). Bodily experiences in secondary school biology. Cultural Studies of Science Education, 6(3), 569-594.

Piqueras, J., Wickman, P.-O., \& Hamza, K. M. (2011). Student teachers' moment-to-moment reasoning and the development of discursive themes. In E. Davidsson, \& A. Jakobsson (Eds.), Understanding interactions at science centers and museums: A sociocultural perspective (pp. 79-96). Rotterdam: SensePublishers B.V.

Richardson, V. (1992). The agenda-setting dilemma in a constructivist staff development process. Teaching and Teacher Education, 8(3), 287-300.

Richmond, G., \& Manokore, V. (2011). Identifying elements critical for functional and sustainable professional learning communities. Science Education, 95(3), 543-570. doi:10.1002/sce.20430.

Roberts, D. A. (1982). Developing the concept of "curriculum emphases" in science education. Science Education, 66(2), 243-260.

Stolk, M., De Jong, O., Bulte, A. W., \& Pilot, A. (2011). Exploring a framework for professional development in curriculum innovation: empowering teachers for designing context-based chemistry education. Research in Science Education, 41(3), 369-388. doi:10.1007/s11165-010-9170-9.

Szteinberg, G., Balicki, S., Banks, G., Clinchot, M., Cullipher, S., Huie, R., et al. (2014). Collaborative professional development in chemistry education research: bridging the gap between research and practice. Journal of Chemical Education, 91(8), 1401-1408. doi:10.1021/ed5003042.

Tytler, R. (2006). School innovation in science: a model for supporting school and teacher development. Research in Science Education, 37(2), 189-216. doi:10.1007/s11165-006-9022-9.

van Driel, J. H., Meirink, J. A., van Veen, K., \& Zwart, R. C. (2012). Current trends and missing links in studies on teacher professional development in science education: a review of design features and quality of research. Studies in Science Education, 48(2), 129-160. doi:10.1080/03057267.2012.738020.

Wickman, P.-O. (2004). The practical epistemologies of the classroom: A study of laboratory work. Science Education, 88(3), 325-344.

Wickman, P.-O. (2006). Aesthetic experience in science education: Learning and meaning-making as situated talk and action (Teaching and Learning in Science Series). New Jersey: Lawrence Erlbaum.

Wickman, P.-O., \& Ligozat, F. (2010). Scientific literacy as action: Consequences for content progression. In C. Linder, L. Östman, D. A. Roberts, P. O. Wickman, \& G. Erickson (Eds.), Exploring the Landscape of Scientific Literacy (pp. 145-159). London: Routledge.

Wickman, P.-O., \& Östman, L. (2002). Learning as discourse change: A sociocultural mechanism. Science Education, 86(5), 601-623.

Witterholt, M., Goedhart, M., Suhre, C., \& van Streun, A. (2012). The interconnected model of professional growth as a means to assess the development of a mathematics teacher. Teaching and Teacher Education, 28(5), 661-674. 